\title{
Penentuan Tingkat Kerawanan Gempa Bumi Menggunakan Metode Refraksi Mikrotremor (ReMi) di Kota Surakarta
}

\author{
Sari Pratiwi", Budi Legowo, Sorja Koesuma \\ Jurusan Fisika FMIPA, Universitas Sebelas Maret \\ *Email: sariipratiwi@gmail.com
}

\section{ABSTRACT}

Surakarta City counted areas who affected by the earthquake. One of efforts to reduce the impact of the earthquake is analyzing the level of seismic hazard as one of the earthquake mitigation with microtremor method which can be known the value of amplification and dominant period. This research has been done in Surakarta City by using P.A.S.I Seismograph Mod. 16S24-P and 3D Borehole geophone GFA Model 60/100. The interval at each location that is $1-3 \mathrm{~km}$ with totally 12 research sites. It takes approximately 20 minutes with three repetitions for the recording data at each location. The microtremor data processing use Geopsy software and Surfer 11 software. Low amplification of zone 1 is a sufficient safe zone to the danger of the earthquakes. Zone 1 is located in Mojo, Moewardi, Sangkrah, Dawung, SMPN 10, Mojosongo, Banyuanyar, Laweyan, Karang Asem and Tipes with the amplification from 0,807314 until 2,60402. The location in type I is a sufficient safe area to the danger of the earthquakes because this type has a thin sediment thickness rather than type II. Type I is located in Mojo, Moewardi, Sangkrah, SMPN 10, Manahan, Mojosong o, Banyuanyar, Laweyan, Karang Asem, Jebres and Tipes with a dominant period between 0,058978s until 0,231411s. Distribution of the vulnerability of the earthquake in Surakarta City can be seen on the zoning map based on the value of $A_{0}$ and $T_{0}$ then, the result can be classified on the zone or in order to obtain certain types of information such as the level of vulnerability and also the type of rock in the ground surface based on the measured parameters.

Keywords: Microtremor, HVSR, Amplification, Dominant Period, Surakarta

\section{ABSTRAK}

Kota Surakarta termasuk wilayah yang mengalami dampak gempa bumi. Salah satu upaya untuk mengurangi dampak dari gempa bumi yaitu melakukan analisa tingkat bahaya seismik sebagai salah satu usaha mitigasi bencana gempa dengan metode mikrotremor yang dapat diketahui nilai amplifikasi dan periode dominan. Pada penelitian telah dilakukan di Kota Surakarta menggunakan P.A.S.I Seis mograph Mod. 16S24-P, 3D Borehole Geophone Model GFA 60/100. Interval pada setiap lokasi yaitu 1-3 km dengan 12 lokasi penelitian. Diperlukan waktu sekitar 20 menit dengan tiga kali pengulangan untuk perekaman data disetiap titik. Pengolahan data mikrotremor menggunakan software Geopsy dan Surfer 11. Hasilnya menunjukkan bahwa amplifikasi rendah pada zona 1 merupakan zona yang cukup aman terhadap bahaya gempa bumi. Zona 1 berada di wilayah Mojo, Moewardi, Sangkrah, Dawung, SMPN 10, Mojosongo, Lapangan Banyuanyar, Laweyan, Karang Asem danTipes dengan amplifikasi 0,807314 sampai dengan 2,60402. Lokasi pada jenis I termasuk wilayah yang cukup aman terhadap gempa bumi karena memiliki ketebalan sedimen yang tipis daripada jenis II. Jenis I berada di wilayah Mojo, Moewardi, Sangkrah, SMPN 10, Manahan, Mojosongo, Banyuanyar, Laweyan, Karang Asem, Jebres dan Tipes dengan periode dominan antara 0,058978s sampai dengan 0,231411s. Sebaran tingkat kerawanan gempa bumi di kota Surakarta dapat dilihat pada peta zonasi berdasarkan nilai $\mathrm{A}_{0}$ dan $\mathrm{T}_{0}$ yang kemudian diklasifikasikan hasilnya pada zona atau jenis tertentu sehingga diperoleh informasi berupa tingkat kerawanan dan juga jenis batuan yang tersusun dibawah permukaan tanah berdasarkan parameter yang diukur.

Kata Kunci: Mikrotremor, HVSR, Amplifikasi, Periode Dominan, Surakarta 


\section{PENDAHULUAN}

Kota Surakarta terletak pada $07^{\circ} 34^{\prime}$ LS dan $110^{\circ} 49^{\prime} 0$ BT dengan luas wilayah kurang lebih $40 \mathrm{~km}^{2}$. Berdasarkan informasi dari letak geografis dan struktur geologi, Kota Surakarta termasuk wilayah yang cenderung mengalami gempa bumi ${ }^{[1]}$. Gempa bumi merupakan fenomena alam berupa gelombang dengan kekuatan yang kecil maupun besar dan dapat menyebabkan kerusakan infastruktur baik besar maupun kecil. Salah satu upaya untuk mengurangi dampak dari gempa bumi yaitu melakukan analisa tingkat bahaya seismik. Kegiatan analisa tingkat bahaya seismik ini merupakan salah satu mitigasi bencana gempa. Pelaksanaan pada mitigasi bencana tersebut yaitu dengan melakukan pengukuran menggunakan metode mikrotremor yang dapat menghasilkan respon dan tingkah laku lapisan tanah atau sedimen terhadap adanya gempa bumi ${ }^{[2,3]}$. Penelitian ini bertujuan untuk mengetahui nilai amplifikasi dan periode dominan di Kota Surakarta dengan menggunakan metode Refraksi Mikrotremor (ReMi). Metode Refraksi Mikrotremor (ReMi) merupakan metode yang dapat merekam penjalaran gelombang geser di bawah permukaan dengan sensor data yang berasal dari sumber medan alami. Penggunaan metode refraksi mikrotremor ini cukup efektif karena wilayah survei yang cukup luas ${ }^{[4]}$. Mikrotremor dapat dikatakan sebagai getaran harmonik alami di bawah permukaan tanah yang terjadi secara terus menerus sehingga terjebak pada lapisan sedimen dan terpantulkan akibat adanya bidang batas lapisan dengan frekuensi tetap yang dikarenakan oleh getaran mikro dan kegiatan alam lainnya di bawah permukaan tanah. Adapun parameter yang dapat diukur dengan metode ini yaitu frekuensi dominan $\left(\mathrm{f}_{0}\right)$, faktor amplifikasi $\left(\mathrm{A}_{0}\right)$, periode dominan $\left(\mathrm{T}_{0}\right)$ dan indeks kerentanan tanah $\left(\mathrm{K}_{g}\right)^{[5]}$.

Metode HVSR merupakan getaran gelombang geser (gelombang $\mathrm{SH}$ ) yang terperangkap pada medium sedimen atau medium yang berada di atas bedrock ${ }^{[7]}$. Adapun persamaan HVSR dinyatakan sebagai berikut ${ }^{[8]}$.

$$
H V S R=\frac{\sqrt{\left(A_{(U-S)}(f)\right)^{2}+\left(A_{(B-T)}(f)\right)^{2}}}{\left(A_{(V)}(f)\right)}
$$

Keterangan:

HVSR = Horizontal to Vertical Ratio

$A_{(U-S)}(f)=$ Nilai amplitudo spektrum frekuensi komponen Utara-Selatan

$A_{(B-T)}(f)=$ Nilai amplitudo spektrum frekuensi komponen Barat-Timur

$A_{(V)}(f) \quad=$ Nilai amplitudo spektrum frekuensi komponen Vertikal 
Tabel 1. Nilai faktor amplifikasi dalam 4 zona ${ }^{[9]}$

\begin{tabular}{cc}
\hline \multicolumn{1}{c}{ Zona } & $\begin{array}{c}\text { Faktor } \\
\text { Amplifikasi }\end{array}$ \\
\hline Zona 1 (amplifikasi rendah) & $\mathrm{Fa}<3$ \\
Zona 2 (amplifikasi sedang) & $3 \leq \mathrm{Fa}<6$ \\
Zona 3 (amplifikasi tinggi) & $6 \leq \mathrm{Fa}<9$ \\
Zona 4 (amplifikasi sangat tinggi) & $\mathrm{Fa} \geq 9$ \\
\hline
\end{tabular}

Perbesaran gelombang seismik yang mengalami perbedaan antar lapisan yang signifikan disebut sebagai amplifikasi ${ }^{[3]}$. Persamaan dari amplifikasi dapat dituliskan sebagai berikut:

$$
A_{0}=\left\{\left\{\left(\rho_{b} . v_{b}\right) /\left(\rho_{s}, v_{s}\right)\right\}\right.
$$

Keterangan:

$\rho_{b} \quad$ : Densitas batuan dasar $(\mathrm{gr} / \mathrm{ml})$

$v_{b} \quad$ : Kecepatan rambat gelombang di batuan dasar $(\mathrm{m} / \mathrm{dt})$

$v_{s} \quad:$ Kecepatan rambat gelombang di batuan lunak $(\mathrm{m} / \mathrm{dt})$

$\rho_{s} \quad$ : Rapat massa dari batuan lunak $(\mathrm{gr} / \mathrm{ml})^{[6]}$

Periode dominan adalah waktu yang diperlukan gelombang mikrotremor merambat pada lapisan endapan sedimen permukaan. Nilai periode dominan dapat menunjukkan karakteristik suatu lapisan di bawah permukaan pada wilayah tertentu saat penelitian berdasarkan klasifikasi yang telah ditetapkan ${ }^{[3]}$. 
Tabel 2. Klasifikasi Tanah Berdasarkan Periode Menurut Kanai ${ }^{[3]}$

\begin{tabular}{|c|c|c|}
\hline $\begin{array}{c}\text { Klasifikasi Tanah } \\
\text { Kanai }\end{array}$ & Periode (T) detik & Keterangan \\
\hline Jenis I & $<0,25$ & $\begin{array}{l}\text { Batuan tersier atau lebih } \\
\text { tua. Terdiri dari batuan } \\
\text { hard sandy, gravel. }\end{array}$ \\
\hline Jenis II & $0,25-0,5$ & $\begin{array}{l}\text { Batuan alluvial dengan } \\
\text { ketebalan } 5 \mathrm{~m} \text {. Terdiri } \\
\text { dari sandy-gravel, sandy } \\
\text { hard clay, loam. }\end{array}$ \\
\hline Jenis III & $0,5-0,75$ & $\begin{array}{l}\text { Batuan alluvial, hampir } \\
\text { sama dengan jenis II, } \\
\text { hanya dibedakan oleh } \\
\text { adanya formasi bluff }\end{array}$ \\
\hline Jenis IV & Lebih dari 0,75 & $\begin{array}{l}\text { Batuan alluvial, yang } \\
\text { terbentuk dari } \\
\text { sedimentasi delta, top } \\
\text { soil, lumpur, dll. Dengan } \\
\text { kedalaman 30m atau } \\
\text { lebih. }\end{array}$ \\
\hline
\end{tabular}

\section{METODE}

Penelitian ini menggunakan metode mikrotremor untuk pengambilan data menggunakan P.A.S.I Seismograph Mod. 16S24-P, 3D Borehole Geophone Model GFA 60/100, accu power supply, dan GPS. Interval yang digunakan pada setiap titik pengukuran yaitu sekitar 1-3 km dengan jumlah 12 titik. Pengambilan data untuk tiap lokasi adalah 20 menit dengan tiga kali pengulangan. Pengukuran koordinat latitude, longitude dan ketinggian dilakukan supaya diketahui posisi pengukuran titik yang akan direkam. Data yang direkam dari metode mikrotremor yaitu berupa file data berformat (.DAT) yang berisi rekaman gelombang natural kemudian file tersebut diolah dengan software Sublime Text 3 untuk menggabungkan file perekaman data, software Geopsy untuk mengolah data menjadi grafik HVSR dan software Surfer 11 untuk proses pembuatan peta mikrozonasi. Tabel 3 dibawah ini adalah lokasi pengukuran mikrotremor. 
Tabel 3. Lokasi pengukuran mikrotremor

\begin{tabular}{ccccc}
\hline Nama Titik & Keterangan & X $(\mathbf{m})$ & Y $(\mathbf{m})$ & Elevasi $(\mathbf{m})$ \\
\hline Lokasi 1 & Mojosongo & 484089,58 & 9165627,17 & 93 \\
Lokasi 2 & Moewardi & 482625,09 & 9164696,17 & 108 \\
Lokasi 3 & Sangkrah & 482215,35 & 9162288,42 & 91 \\
Lokasi 4 & Dawung & 480333,16 & 9161086,03 & 94 \\
Lokasi 5 & SMPN 10 & 480112,77 & 9163503,69 & 94 \\
Lokasi 6 & Manahan & 479174,37 & 9165149,31 & 97 \\
Lokasi 7 & Mojosongo & 481312,81 & 9166544,38 & 118 \\
Lokasi 8 & Banyuanyar & 478879,62 & 9166454,33 & 99 \\
Lokasi 9 & Laweyan & 476826,15 & 9163756,19 & 102 \\
Lokasi 10 & Karang Asem & 475638,00 & 9165163,01 & 108 \\
Lokasi 11 & Jebres & 483052,98 & 9163555,79 & 93 \\
Lokasi 12 & Tipes & 479065,31 & 9162256,45 & 95 \\
\hline
\end{tabular}

\section{HASIL DAN PEMBAHASAN}

Hasil dari penelitian diperoleh peta zonasi dari amplifikasi (Gambar 1). Pada zona 1 merupakan amplifikasi rendah karena memiliki amplifikasi antara 0,807314 sampai dengan 2,60402. Adapun lokasi tersebut berada di wilayah Mojo, Moewardi, Sangkrah, Dawung, SMPN 10, Mojosongo, Banyuanyar, Laweyan, Karang Asem dan Tipes. Pada zona 2 merupakan amplifikasi sedang atau mempunyai risiko sedikit lebih tinggi dibanding zona 1, karena mempunyai amplifikasi 3,19811 dan 4,13874 yaitu di lokasi 6 dan 11. Hasil penelitian dari nilai amplifikasi yang diperoleh, zona 1 termasuk zona yang cukup aman dari guncangan gempa bumi, dibanding lokasi pada zona 2.

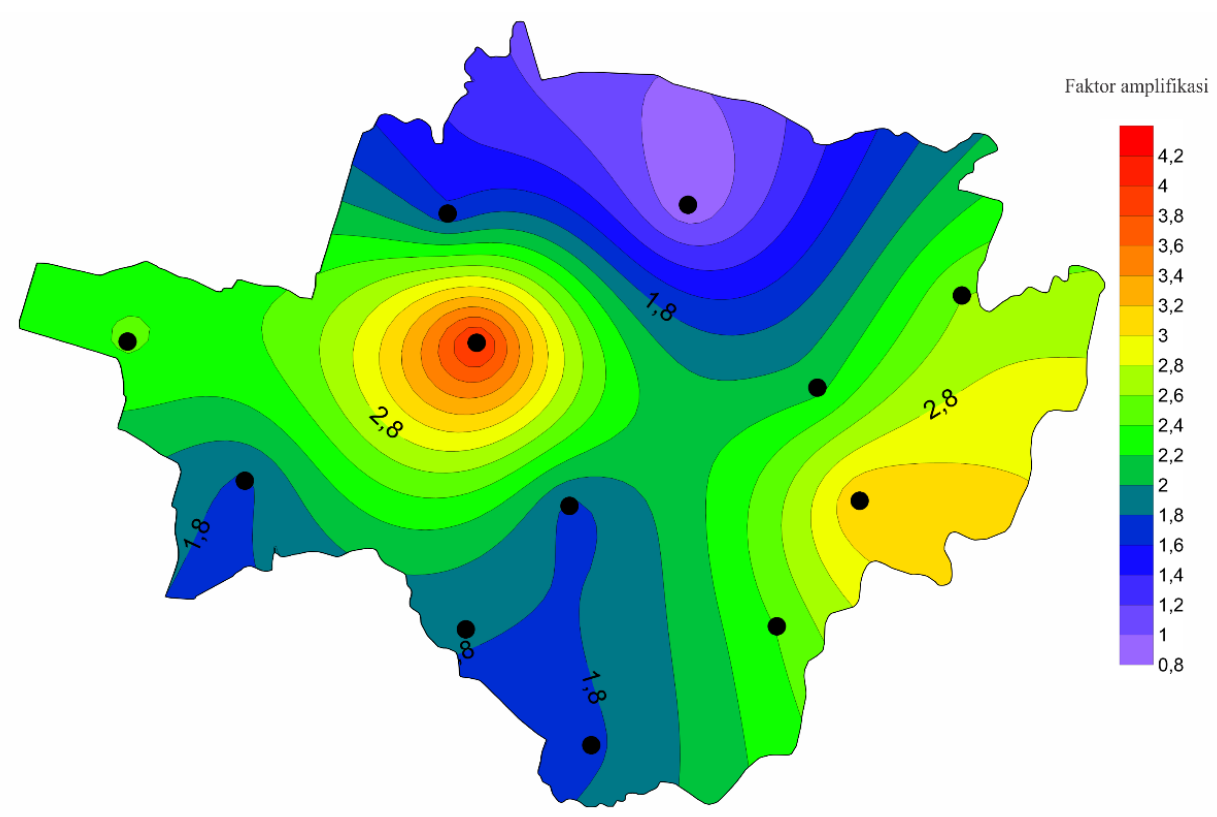

Gambar 1. (color online) Peta Zonasi Amplifikasi 
Untuk periode dominan dilakukan perhitungan terlebih dahulu dengan persamaan (3) untuk membuat peta zonasi berdasarkan nilai periode dominan (Gambar 2).

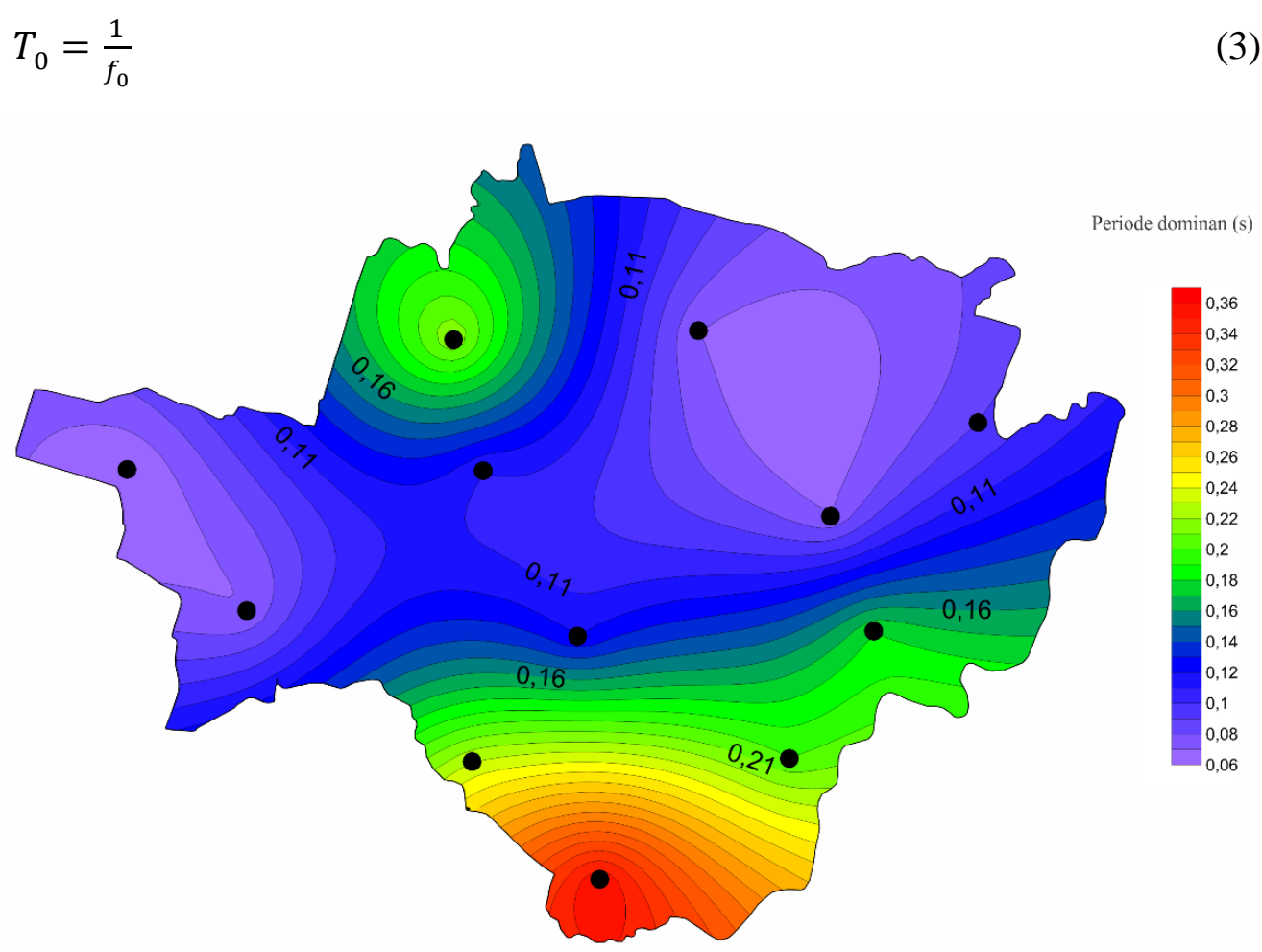

Gambar 2. (color online) Peta Zonasi Periode Dominan

Berdasarkan hasil yang diperoleh lokasi 1, 2, 3, 5, 6, 7, 8, 9, 10, 11, 12 merupakan jenis 1 dengan periode dominan antara 0,058978s sampai dengan 0,231411s. Adapun lokasi ini berada di wilayah Mojo, Moewardi, Sangkrah, SMPN 10, Manahan, Mojosongo, Banyuanyar, Laweyan, Karang Asem, Jebres dan Tipes. Kemudian lokasi 4 yaitu di Dawung merupakan jenis 2 dengan periode 0,356757s. Berdasarkan hasil yang diperoleh dketahui bahwa jenis I merupakan wilayah yang cukup aman dari guncangan gempa bumi karena memiliki nilai periode yang lebih kecil dari 0,25 detik. Sedangkan pada lokasi Dawung dan sekitarnya merupakan daerah yang cukup rawan terjadi kerusakan apabila terjadi gempa bumi karena mempunyai periode yang lebih besar dari 0,25 detik.

\section{KESIMPULAN}

Nilai amplifikasi di Kota Surakarta terbagi dalam dua zona yaitu zona 1 dan zona 2. Zona 1 merupakan zona yang cukup aman terhadap bahaya gempa bumi karena memiliki amplifikasi yang rendah (Mojo, Moewardi, Sangkrah, Dawung, SMPN 10, Mojosongo, Banyuanyar, Laweyan, Karang Asem dan Tipes). Sedangkan Zona 2 mempunyai amplifikasi sedang atau mempunyai risiko sedikit lebih tinggi (Manahan dan Jebres). Nilai periode dominan di Kota Surakarta terbagi dalam dua jenis yaitu jenis I dan II. Jenis I merupakan formasi geologi yang terdiri dari batuan tersier atau lebih tua (hard sandy, gravel). Lokasi pada jenis I (Mojo, Moewardi, Sangkrah, SMPN 10, Manahan, Mojosongo, Banyuanyar, Laweyan, Karang Asem, Jebres dan Tipes) termasuk wilayah yang cukup aman terhadap 
gempa bumi karena memiliki ketebalan sedimen yang tipis daripada jenis II (Dawung). Jenis II merupakan formasi geologi yang terdiri dari batuan alluvial (sandy-gravel, sandy hard clay, loam).

\section{DAFTAR PUSTAKA}

1 Ani, Ari Yuni. 2011. Analisa Struktur Bawah Permukaan di Wilayah Surakarta Menggunakan Metode Gravitasi. Skripsi. Departemen Fisika Surakarta Universitas Sebelas Maret.

2 Irsyam, Masyhur., Sengara, Wayan., Aldiamar, Fahmi., Widiyantoro, Sri., Triyoso, Wahyu., Hilman, Danny., Kertapati, Engkon., Meilano, Irwan., Suhardjono., Asrurifak, M., Ridwan, M., Hutabarat, Daniel., Sidi, Indra Jati., Merati, Widiadnyana. 2010. Development of Seismic Hazard and Risk Maps for New Seismic Building and Infrastructure Codes in Indonesia. Proceeding the $6^{\text {th }}$ Engineering Conference in Asia Region: Embracing the Future through Sustainability. ISBN 1978-602-8605-08-3.

3 Arifin, Satria Subkhi., Mulyatno, Bagus Sapto., Marjiyono., Setianegara, Roby. (2014). Penentuan Zona Rawan Guncangan Bencana Gempa Bumi Berdasarkan Analisis Nilai Amplifikasi HVSR Mikrotremor dan Analisis Periode Dominan Daerah Liwa dan Sekitarnya. Jurnal Eksplorasi. Vol 2/No.1.

4 Nurrahmi., Efendi, Rustan., Sandra. 2015. Analis is Kecepatan Gelombang Geser Vs30 Menggunakan Metode Refraksi Mikrotremor (ReMi) di Kelurahan Talise. Gravitasi.Vol. 14 No.1 ISSN: 1412-2375.

5 Harahap, Reza Agus Parlindungan., Fatmawati, Laily Endah., Soemitro, Ria Asih Aryani., Satrya, Trihanyndio Rendy. 2013. Analisa Mikrotremor Dengan Metode HVSR (Horizontal to Vertical Spectral Ratio) untuk Pemetaan Mikrozonasi di Kelurahan Kejawan Puth Tambak Surabaya. Jurnal Teknik POMITS. VOL. 1, NO. 1, $1-4$.

6 Nakamura, Yutaka. 2008. On The H/V Spectrum. The $14^{\text {th }}$ World Conference on Earthquake Engineering October 12-17, 2008, Beijing, China.

7 Mucciarelli, M., Other, C., Gosar, D., Herak, A., Albarello, M. (2008). Assesment of Seismic Site Amplification and of Seismic Building Vulnerability in the Republic of Macedonia, Croatia and Slovenia. The $14^{\text {th }}$ World Conference on Earthquake Engineering October 12-17.2008, Beijing, China.

8 Wibowo, Nugroho Budi. (2015). Spatial Anaysis of Surface Aquifer Thickness Based Frequency predominan in Bantul District. Indonesian Journal of Applied Physics. Vol.5 No.1 Hal.62.

9 BMKG. (2010). Kajian Kerawanan Bahaya Gempabumi di kabupaten Bantul, DIY. Laporan Hasil Pekerjaan. Pusat Penelitian dan Pengembangan Badan Meteorologi Klimatologi dan Geofisika. 